\title{
Effect of preoperative chemoradiotherapy on perioperative outcomes in patients undergoing laparoscopic rectal cancer surgery
}

\author{
Ulaş Aday, ${ }^{1}$ Abdullah Böyük ${ }^{2}$ \\ 'Department of Gastroenterological Surgery, Elazığ Fethi Sekin City Hospital, Elazığ, Turkey \\ 2Department of Surgery, Elazığ Fethi Sekin City Hospital, Elazığ, Turkey
}

\begin{abstract}
Introduction: The aim of this study was to investigate the effect of neoadjuvant chemoradiotherapy (nCRT) on perioperative outcomes in patients who underwent laparoscopic rectal cancer surgery.

Materials and Methods: This retrospective study included patients who underwent laparoscopic surgery due to rectal adenocarcinoma between January 2017 and March 2019. Patients who underwent open surgery, transanal excision, or additional resection due to metastasis were excluded from the study. Demographic, clinical, and pathological characteristics of the patients were recorded. Perioperative complications were categorized according to the extended Clavien-Dindo classification.

Results: The 61 patients enrolled in the study comprised 35 (57.4\%) patients who received nCRT (nCRT group) and 26 (42.6\%) patients who did not receive nCRT (non-nCRT group). The mean age was 54.6 \pm 12.9 years in the nCRT group and $62 \pm 14.8$ years in the non-nCRT group, which represented a significant difference between the 2 groups $(p=0.048)$. The groups were similar with regard to comorbidities, body mass index, American Society of Anesthesiologists score, pathological staging, and length of hospital stay. The mean operative time was $298 \pm 36.8$ minutes in the nCRT group and $243 \pm 50.2$ minutes in the non-nCRT group, which amounted to a significant difference $(\mathrm{p}<0.001)$. The classification of complications indicated Grade I, II, III, and IV complications in 16 (45.7\%), 15 (42.8\%), 3 (8.6\%), and 1 (2.9\%) patients, respectively, in the nCRT group as opposed to $16(61.6 \%), 8(30.8 \%), 1(3.8 \%)$, and 1 (3.8\%), respectively, in the non-nCRT group, and no significant difference was found between the 2 groups $(p=0.606)$.

Conclusion: The results indicated that nCRT had no effect on perioperative complications and resulted in longer operative times in laparoscopic rectal cancer surgery.
\end{abstract}

Keywords: Laparoscopic surgery; neoadjuvant chemoradiotherapy; rectal cancer.

\section{Introduction}

Laparoscopic colorectal surgery has been well accepted worldwide, offering similar oncological outcomes to open surgery, reduced analgesic requirement, early mo- bilization, and shorter hospitalization without additional complications. Neoadjuvant chemoradiotherapy (nCRT) followed by total mesorectal excision (TME) has become 
the standard treatment for locally advanced rectal cancer. ${ }^{[1,2]}$ nCRT has been shown to offer several advantages including improved local control, good tolerance, tumor downstaging, and complete pathological response (cPR. ${ }^{[3,4]}$ On the other hand, nCRT has been shown to be associated with increased perioperative complications and to present challenges for laparoscopic surgery due to a number of factors including increased operative time, radiation-induced edema, and fibrosis. ${ }^{[5,6]}$ In contrast, recent studies and meta-analyses have indicated that the nCRTinduced perioperative complications have been reduced with the increase in laparoscopic experience and nCRT has similar morbidity and mortality rates to those of open surgery in the laparoscopic treatment of rectal cancer. [1,2,7-14] Additionally, the documentation of long-term oncological outcomes comparable to those of open surgery has eliminated concerns about the oncological outcomes of laparoscopic rectal cancer surgery. ${ }^{[8,15]}$ In the present study, we aimed to investigate the effect of nCRT on perioperative outcomes in patients undergoing laparoscopic rectal cancer surgery.

\section{Materials and Methods}

The retrospective study included patients that underwent laparoscopic surgery due to rectal adenocarcinoma in our clinic between January 1, 2017 and March 31, 2019. The study was approved by the local ethics committee. Patients with a rectal tumor at $15 \mathrm{~cm}$ from the anal verge, an endoscopic biopsy of rectal adenocarcinoma, and patients that underwent surgery under elective conditions and completed surgery with laparoscopy were included in the study. Patients with adjacent organ invasion (T4) and patients that underwent open surgery, additional resection due to metastasis, and transanal excision were excluded from the study. Each patient underwent oral and intravenous contrast-enhanced abdomino-pelvic and thoracic computed tomography (CT) and pelvic magnetic resonance imaging (MRI) for tumor staging. nCRT was performed in the patients that were detected with T3-T4 and/or lymph node metastasis on radiological examination. Long-term radiotherapy was performed with a total of 45-50.4 Gy administered in 28 sessions, and the concurrent chemotherapy was performed with capecitabin. Curative surgery was performed 8-12 weeks after the completion of radiotherapy. The surgical procedure was administered by the same surgical team for all the patients. Sphincter-preserving resection (SPR) was performed with complete splenic flexure and left colon mobilization in a medial to lateral and superior to inferior fashion. TME was administered using the standard procedure. ${ }^{[16,17]} \mathrm{A}$ standard pathologic examination was performed for all the resected specimens. Each specimen was evaluated for tumor differentiation, depth of tumor penetration, and lymph node metastases. Age, gender, body mass index (BMI), diverting ileostomy, operative time, American Society of Anesthesiologists (ASA) score, length of hospital stay, and postoperative course were recorded for each patient. Perioperative complications were classified according to the extended Clavien-Dindo classification. ${ }^{[18]}$ The patients were divided into two groups as nCRT and non-nCRT.

\section{Statistical Analysis}

Data were analyzed using SPSS for Windows (IBM SPSS, Armonk, NY, USA). Descriptives were expressed as mean, standard deviation (SD), and percentages. Normal distribution of data was analyzed using Kolmogorov-Smirnov test. Parametric data were compared using Student's ttest and nonparametric data were compared using MannWhitney $U$ test and Chi-square test. A $p$ value of $<0.05$ was considered significant.

\section{Results}

A total of 77 patients underwent curative surgery due to rectal adenocarcinoma between January 1, 2017 and March 31, 2019. Of these, 16 patients were excluded from the study based on the exclusion criteria and thus 61 patients were included in the study (Fig. 1). The 61 patients comprised 35 (57.4\%) patients that received nCRT (nCRT group) and $26(42.6 \%)$ patients that did not receive nCRT

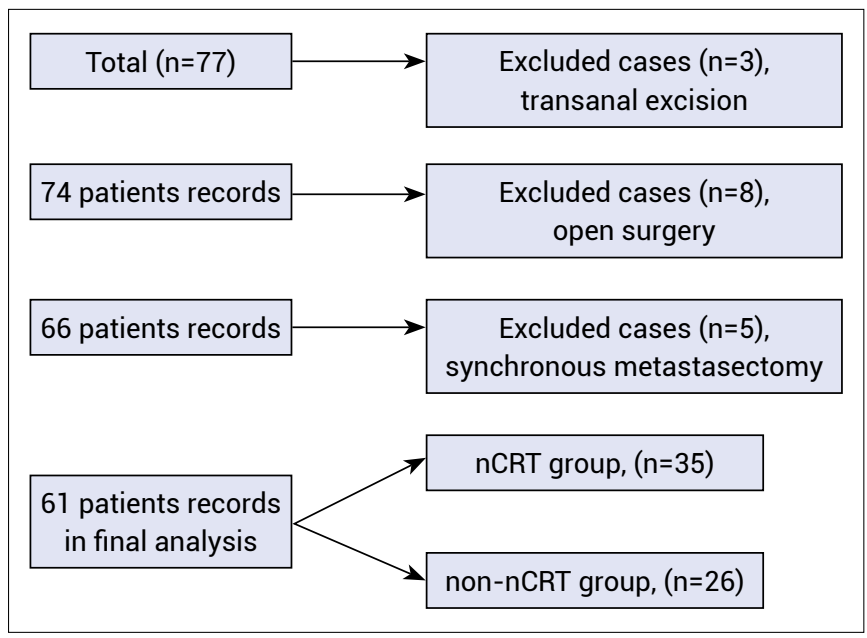

Figure 1. Flow chart of this study. nCRT: Neoadjuvant chemoradiotherapy. 
(non-nCRT group). Mean age was $54.6 \pm 12.9$ years in the nCRT group and $62 \pm 14.8$ years in the non-nCRT group and a significant difference was found between the two groups $(\mathrm{p}=0.048)$. The groups were similar with regard to comorbidities, BMI, ASA score, pathological staging, and length of hospital stay. Twenty (86.9\%) out of 23 patients with a lower rectal tumor underwent nCRT $(\mathrm{p}<0.001)$. Table 1 presents the demographic, clinical, and pathological characteristics of the patients. SPR was performed in 50 (81.9\%) and abdominoperineal resection (APR) was performed in $11(18.1 \%)$ patients. Of the patients that underwent APR, 10 (90.9\%) of them received nCRT ( $p=0.013)$. Mean operative time was $298 \pm 36.8 \mathrm{~min}$ in the $\mathrm{nCRT}$ group and $243 \pm 50.2 \mathrm{~min}$ in the non-nCRT group $(\mathrm{p}<0.001)$. A diverting ileostomy was performed in $40(80 \%)$ of the pa- tients that underwent SPR and in almost all the patients that underwent nCRT $(\mathrm{n}=24 ; 96 \%)$.

Throughout the surgery, no organ injury occurred in the adjacent organs such as ureter, spleen, or pancreas. Nevertheless, postoperative ileus, surgical site infection, bleeding, atelectasis, and urine retention were the most common complications (Table 2). Complications occurred in 21 and 14 patients in the nCRT and non-nCRT groups, respectively, and some of these patients had multiple complications. The classification of complications indicated Grade I, II, III, and IV complications in 16 (45.7\%), 15 (42.8\%), 3 (8.6\%), and 1 (2.9\%) patient in the nCRT group as opposed to $16(61.6 \%), 8(30.8 \%), 1(3.8 \%)$, and $1(\%$ 3.8) patient in the non-nCRT group, respectively, and no significant difference was found between the two groups

Table 1. Clinical and pathological characteristics

\begin{tabular}{|c|c|c|c|}
\hline Characteristic & $\begin{array}{l}\text { nCRT group } \\
\quad(n=35)\end{array}$ & $\begin{array}{c}\text { non-nCRT group } \\
(n=26)\end{array}$ & $\mathbf{p}$ \\
\hline Age (years), mean $\pm S D$ & $54.6 \pm 12.9$ & $62 \pm 14.8$ & 0.048 \\
\hline \multicolumn{4}{|l|}{ Sex, n (\%) } \\
\hline Male & $20(57.1)$ & $18(69.2)$ & \multirow[t]{2}{*}{0.335} \\
\hline Female & $15(42.8)$ & $8(30.7)$ & \\
\hline \multicolumn{4}{|l|}{ Comorbidity, n (\%) } \\
\hline Yes & $13(37.1)$ & $10(38.4)$ & \multirow[t]{2}{*}{0.916} \\
\hline No & $22(62.8)$ & $16(61.5)$ & \\
\hline Body mass index $\left(\mathrm{kg} / \mathrm{m}^{2}\right)$, mean $\pm S D$ & $27.6 \pm 3.6$ & $27.6 \pm 3.4$ & 0.986 \\
\hline \multicolumn{4}{|l|}{ Tumor localization, $\mathrm{n}(\%)$} \\
\hline Lower & $20(57.1)$ & $3(11.5)$ & \multirow[t]{3}{*}{$<0.001$} \\
\hline Middle & $11(31.4)$ & $7(26.9)$ & \\
\hline Upper & $4(11.4)$ & $16(61.5)$ & \\
\hline \multicolumn{4}{|l|}{ ASA classification, $\mathrm{n}(\%)$} \\
\hline 1 & $7(20)$ & $6(23)$ & \multirow[t]{3}{*}{0.550} \\
\hline II & $22(62.8)$ & $13(50)$ & \\
\hline III & $6(17.1)$ & $7(27)$ & \\
\hline \multicolumn{4}{|l|}{ Operative type, $\mathrm{n}(\%)$} \\
\hline Sphincter saving & $25(71.4)$ & $25(96.1)$ & \multirow[t]{2}{*}{0.013} \\
\hline APR & $10(28.5)$ & $1(3.8)$ & \\
\hline Operative time, mean $\pm S D$ & $298 \pm 36$ & $243.4 \pm 50$ & $<0.001$ \\
\hline \multicolumn{4}{|l|}{ Pathologic stage, n (\%) } \\
\hline 0 & $5(14.2)$ & $1(3.8)$ & \multirow[t]{4}{*}{0.429} \\
\hline 1 & $13(37.1)$ & $11(42.3)$ & \\
\hline II & $8(22.8)$ & $9(34.6)$ & \\
\hline III & $9(25.7)$ & $5(19.2)$ & \\
\hline Mean hospital stay (days), mean $\pm S D$ & $10.48 \pm 5.5$ & $9 \pm 3.3$ & 0.199 \\
\hline
\end{tabular}


Table 2. Postoperative complications

\begin{tabular}{lcc} 
& $\begin{array}{c}\text { nCRT } \\
\text { group } \\
(\mathbf{n = 3 5})\end{array}$ & $\begin{array}{c}\text { Non-nCRT } \\
\text { group } \\
(\mathbf{n}=\mathbf{2 6})\end{array}$ \\
\hline Wound infection & 6 & 1 \\
Ileus & 5 & 3 \\
Bleeding & 3 & 1 \\
Pulmonary complications & 1 & 4 \\
Bladder dysfunction & 0 & 2 \\
Acute renal failure & 0 & 2 \\
Pelvic abscess & 2 & 0 \\
Leakage & 1 & 0 \\
Bone marrow suppression & 1 & 0 \\
Radial nerve neuropathy & 1 & 0 \\
Gastroparesis & 0 & 1 \\
Sepsis & 1 & 0 \\
Total & 21 & 14 \\
\hline nCRT: Neoadjuvant chemoradiotherapy. & & \\
\hline
\end{tabular}

$(\mathrm{p}=0.606)$ (Table 3). Mean length of hospital stay was $10.4 \pm 5.5$ days in the nCRT group and $9 \pm 3.3$ days in the nonnCRT group and no significant difference was established $(p=0.199)$. No mortality occurred in any patient within the first 30 days after surgery.

\section{Discussion}

The results indicated that nCRT did not increase perioperative complications when administered prior to laparoscopic rectal cancer surgery. Moreover, based on the Clavien-Dindo classification, Grade III complications, which require invasive procedures, were detected in 3 and 1 patients in the nCRT and non-nCRT groups, respectively, and no significant difference was found between the two groups although the incidence was higher in the nCRT group compared to the non-nCRT group ( $\mathrm{p}=0.606)$. Grade IV complications were detected in one patient in each group. In these patients, a stoma was created in the one patient in the nCRT group due to anastomotic leakage and the loop ileostomy was converted to an end ileostomy in the patient in the non-nCRT group due to fascial stenosis. Mean operative time was $298 \pm 36.8 \mathrm{~min}$ in the nCRT group and $243 \pm 50.2 \mathrm{~min}$ in the non-nCRT group and a significant difference was found $(p<0.001)$. The longer operative time in the nCRT group could be attributed to the higher rate of ileostomy in this group. On the other hand, it is commonly known that radiation-induced complications such as inflammation, exudation, edema, and fibrosis present challenges for dissection, thereby leading to increased operative times and intraoperative blood loss. ${ }^{[13,19]}$

Based on randomized controlled trials demonstrating a significantly lower incidence of local relapse in patients receiving nCRT compared to adjuvant therapy, the National Comprehensive Cancer Network guidelines currently recommend nCRT for patients with stage II and III rectal cancer. Neoadjuvant radiation may offer several other advantages in comparison to adjuvant radiation such as increased sensitivity to radiation, reduced tumor volume allowing for a sphincter-preserving operation and less postoperative adhesions by avoiding radiationinduced injury to the surrounding small bowel. ${ }^{[3,4,9,20,21]}$ On the other hand, laparoscopic rectal cancer surgery has recently emerged as a popular technique due to the advancements in medical technology and the increasing experience of surgeons. Moreover, its encouraging shortterm outcomes and the documentation of long-term oncological outcomes comparable to those of open surgery in randomized controlled studies and meta-analyses have eliminated concerns about the oncological outcomes of laparoscopic rectal cancer surgery. ${ }^{[2,8,15,22-24]}$ In a previous large series, Chapman et al. ${ }^{[9]}$ evaluated patients that underwent surgery for rectal cancer and found no significant difference between the patients that underwent neoadjuvant chemoradiation followed by surgery and patients that underwent surgery alone with regard to overall

Table 3. Distribution of complications according to Clavien Dindo classification

\begin{tabular}{lccc} 
Clavien Dindo classification $(\mathbf{n}, \%)$ & nCRT group $(\mathbf{n = 3 5 )}$ & non-nCRT group (n=26) & p \\
\hline I & $16(45.7)$ & $16(61.6)$ & 0.606 \\
II & $15(42.8)$ & $8(30.8)$ & \\
III & $3(8.6)$ & $1(3.8)$ & \\
IV & $1(2.9)$ & $1(3.8)$ & \\
\hline
\end{tabular}

nCRT: Neoadjuvant chemoradiotherapy. 
morbidity and 30-day mortality. In a meta-analysis that mostly reviewed randomized controlled studies and compared open and laparoscopic surgery, Lu et al ${ }^{[2]}$ suggested that laparoscopy is a safe procedure to be administered after nCRT in patients with middle and lower rectal cancer.

Our study was limited since it had a retrospective design and a limited number of patients and had no long-term results. Moreover, no comparison was made between the patients that underwent open and laparoscopic surgery. Finally, the study presented findings from a single center and thus was not a multicenter study.

\section{Conclusion}

It was revealed that nCRT has no effect on perioperative complications despite leading to longer operative times in laparoscopic rectal cancer surgery. Accordingly, laparoscopic surgery can be safely performed following nCRT in patients with rectal cancer.

\section{Disclosures}

Ethichs Committee Approval: The study was approved by the Local Ethics Committee.

Peer-review: Externally peer-reviewed.

Conflict of Interest: None declared.

\section{References}

1. Ishihara S, Watanabe T, Fukushima $\mathrm{Y}$, Akahane $\mathrm{T}$, Horiuchi A, Shimada $R$, et al. Safety and factors contributing to the difficulty of laparoscopic surgery for rectal cancer treated with preoperative chemoradiotherapy. Tech Coloproctol 2014;18:247-55. [CrossRef]

2. Lu Y, Peng L, Ma Y, Liu Y, Ren L, Zhang L. Comparison Between Laparoscopic and Open Resection Following Neoadjuvant Chemoradiotherapy for Mid-Low Rectal Cancer Patients: A Meta-Analysis. J Laparoendosc Adv Surg Tech A 2019;29:316-22. [CrossRef]

3. Rahbari NN, Elbers H, Askoxylakis V, Motschall E, Bork U, Büchler MW, et al. Neoadjuvant radiotherapy for rectal cancer: meta-analysis of randomized controlled trials. Ann Surg Oncol 2013;20:4169-82. [CrossRef]

4. Sauer R, Becker H, Hohenberger W, Rödel C, Wittekind C, Fietkau $\mathrm{R}$, et al. Preoperative versus postoperative chemoradiotherapy for rectal cancer. N Engl J Med 2004;351:173140. [CrossRef]

5. Konishi T, Watanabe T, Kishimoto J, Nagawa H. Elective colon and rectal surgery differ in risk factors for wound infection: results of prospective surveillance. Ann Surg 2006;244:75863. [CrossRef]

6. Marijnen CA, Kapiteijn E, van de Velde CJ, Martijn H, Steup
WH, Wiggers T, et al; Cooperative Investigators of the Dutch Colorectal Cancer Group. Acute side effects and complications after short-term preoperative radiotherapy combined with total mesorectal excision in primary rectal cancer: report of a multicenter randomized trial. J Clin Oncol 2002;20:81725. [CrossRef]

7. Ahn BH, Lee KH, Park JB, Song MS, Kim JY, Kim JS. Shortterm outcomes after laparoscopic surgery following preoperative chemoradiotherapy for rectal cancer. J Korean Surg Soc 2012;83:281-7. [CrossRef]

8. Zheng J, Feng X, Yang Z, Hu W, Luo Y, Li Y. The comprehensive therapeutic effects of rectal surgery are better in laparoscopy: a systematic review and meta-analysis. Oncotarget 2017;8:12717-29. [CrossRef]

9. Chapman BC, Hosokawa P, Henderson W, Paniccia A, Overbey DM, Messersmith W, et al. Impact of neoadjuvant chemoradiation on perioperative outcomes in patients with rectal cancer. J Surg Oncol 2017;115:1033-44. [CrossRef]

10. Valenti V, Hernandez-Lizoain JL, Baixauli J, Pastor C, Aristu J, Diaz-Gonzalez J, et al. Analysis of early postoperative morbidity among patients with rectal cancer treated with and without neoadjuvant chemoradiotherapy. Ann Surg Oncol 2007; 14:1744-51. [CrossRef]

11. Ulrich $A$, Weitz J, Slodczyk $M$, Koch $M$, Jaeger $D$, Münter $M$, et al. Neoadjuvant treatment does not influence perioperative outcome in rectal cancer surgery. Int $\mathrm{J}$ Radiat Oncol Biol Phys 2009;75:129-36. [CrossRef]

12. Denoya $P$, Wang $H$, Sands $D$, Nogueras J, Weiss E, Wexner SD. Short-term outcomes of laparoscopic total mesorectal excision following neoadjuvant chemoradiotherapy. Surg Endosc 2010;24:933-8. [CrossRef]

13. Seshadri RA, Srinivasan A, Tapkire R, Swaminathan R. Laparoscopic versus open surgery for rectal cancer after neoadjuvantchemoradiation: a matched case-control study of shortterm outcomes. Surg Endosc 2012;26:154-61. [CrossRef]

14. Holubar SD, Brickman RK, Greaves SW, Ivatury SJ. Neoadjuvant Radiotherapy: A Risk Factor for Short-Term Wound Complications after Radical Resection for Rectal Cancer? J Am Coll Surg 2016;223:291-8. [CrossRef]

15. Seshadri RA, Swaminathan R, Srinivasan A. Laparoscopic versus open surgery for rectal cancer after neoadjuvant chemoradiation: Long-term outcomes of a propensity score matched study. J Surg Oncol 2018;117:506-13. [CrossRef]

16. Böyük A, Aday U, Gültürk B, Bozdağ A, Aksu A, Kutluer N. Effect of splenic flexure mobilization performed via medialto-lateral and superior-to-inferior approach on early clinical outcomes in elective laparoscopic resection of rectal cancer. Available at: https://doi.org/10.5114/wiitm.2019.85224. Accessed June 21, 2019. [CrossRef]

17. Heald RJ, Ryall RD. Recurrence and survival after total mesorectal excision for rectal cancer. Lancet 1986;1:147982. [CrossRef]

18. Katayama H, Kurokawa $\mathrm{Y}$, Nakamura $\mathrm{K}$, Ito $\mathrm{H}$, Kanemitsu $\mathrm{Y}$, Masuda $\mathrm{N}$, et al. Extended Clavien-Dindo classification of surgical complications: Japan Clinical Oncology Group post- 
operative complications criteria. Surg Today 2016;46:66885. [CrossRef]

19. Akiyoshi $T$, Kuroyanagi $H$, Oya M, Konishi T, Fukuda M, Fujimoto $Y$, et al. Safety of laparoscopic total mesorectal excision for low rectal cancer with preoperative chemoradiation therapy. J Gastrointest Surg 2009;13:521-5. [CrossRef]

20. NCCN Clinical Practice Guidelines in Oncology. Rectal cancer. 2019. Available at: http://www.nccn.org. Accessed June 21, 2019.

21. van Gijn W, Marijnen CA, Nagtegaal ID, Kranenbarg EM, Putter $\mathrm{H}$, Wiggers $\mathrm{T}$, et al. Preoperative radiotherapy combined with total mesorectal excision for resectable rectal cancer: 12-year follow-up of the multicentre, randomised controlled TME trial. Lancet Oncol 2011;12:575-82. [CrossRef]

22. Bonjer HJ, Deijen $\mathrm{CL}$, Abis GA, Cuesta MA, van der Pas MH, de Lange-de Klerk ES, et al. A randomized trial of laparo- scopic versus open surgery for rectal cancer. N Engl J Med 2015;372:1324-32. [CrossRef]

23. Kang SB, Park JW, Jeong SY, Nam BH, Choi HS, Kim DW, et al. Open versus laparoscopic surgery for mid or low rectal cancer after neoadjuvant chemoradiotherapy (COREAN trial): short-term outcomes of an open-label randomised controlled trial. Lancet Oncol 2010;11:637-45. [CrossRef]

24. Jeong SY, Park JW, Nam BH, Kim S, Kang SB, Lim SB, et al. Open versus laparoscopic surgery for mid-rectal or low-rectal cancer after neoadjuvant chemoradiotherapy (COREAN trial): survival outcomes of an open-label, non-inferiority, randomised controlled trial. Lancet Oncol 2014;15:767-74.

- This study was presented as an oral presentation at the $14^{\text {th }}$ National ELCD Congress (19-22 April 2019, Cyprus). 